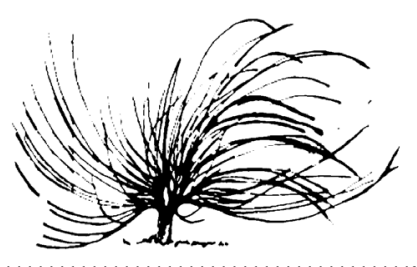

\title{
La democracia rural en el aula: ideología, debate y cuestionamiento actual de los estudios sociales
}

\author{
Maximiliano López López ${ }^{1}$ \\ Universidad Nacional \\ Costa Rica \\ maxmlopez6@gmail.com
}

\begin{abstract}
“... se aprecian muestras de tentación totalitaria de la política respecto de la educación, tentación que, siguiendo el camino de una degeneración de la política, se manifiesta en un excesivo control sobre los procesos educativos (...). La posición más extrema de esta asunción totalitaria se expresa en la voluntad de "diseñar la sociedad diseñando el niño".
\end{abstract}

(Vázquez, 2015, p. 20)

\begin{abstract}
Resumen
Este ensayo pretende demostrar que el papel ideológico de la Enseñanza de los Estudios Sociales en Costa Rica no es nuevo como se intentó presentar en 2018, en los medios de comunicación y en el seno de la clase política. Para ello, se hará primero un acercamiento al tema de la ideología, hegemonía y educación con el fin de aportar algunos elementos teóricos que ayuden a comprender esta relación. Seguidamente, se verá que, desde la misma creación de los Estudios Sociales como materia escolar,
\end{abstract}

Recibido: 11 de setiembre de 2019. Aprobado: 29 de abril de 2020.

http://dx.doi.org/10.15359/rep.15-2.3

1 Es máster en Historia Aplicada y máster en Pedagogía con énfasis en Atención a la Diversidad. Profesor e investigador de la Escuela de Historia de la Universidad Nacional de Costa Rica (UNA). Participa del equipo de investigación del Observatorio de Historia Agroecológica y Ambiental (OHAA) y es miembro de la Sociedad Latinoamericana y Caribeña de Historia Ambiental (SOLCHA) y de la Red Centroamericana de Investigación y Docencia en Estudios Sociales y Ciudadanía Crítica (RECIDEC). Fue coordinador de la Revista Perspectivas de la Escuela de Historia y se desempeñó como subdirector y luego director de la Escuela de Historia entre 2011 y 2017. Este trabajo se inscribe en la labor que impulsa la RECIDEC. Código ORCID: https://orcid.org/0000-0003-3175-1731 
su concepción estuvo marcada por un fuerte sesgo hacia la historia patria y los valores democráticos atribuidos a un pasado, colonial e independiente, presuntamente caracterizado por el consenso y la igualdad. Luego se hace la revisión de algunos programas de esta asignatura, posteriores a 1970, con el objetivo de evidenciar las cargas ideológicas que el Estado le asignó a dicha materia en la formación de niños y jóvenes del país. Como telón de fondo, el ensayo busca plantear que estas inquietudes sobre el papel ideológico de los estudios sociales eclosionan en un momento histórico caracterizado por profesionales en educación que han asumido la pedagogía crítica como su principal herramienta de disenso.

Palabras clave: Costa Rica, educación, Estudios Sociales, ideología, pedagogía crítica

\begin{abstract}
This essay seeks to demonstrate that the ideological role of the teaching of Social Studies is not new despite having been presented as such in 2018 by the media and the political class. In order to do so, first, the topics of ideology, hegemony, and education will be touched on to establish some theoretical elements that can help understand this relationship. Next, this paper will show that, since its inception as a school subject, Social Studies markedly emphasized national history and the democratic values associated with a colonial, independent past, supposedly characterized by consensus and equality. Then, some study programs for this subject subsequent to 1970 are revisited in order to show the ideological load that the state assigned to this subject. Finally, this essay seeks to put forward that the debate on the ideological role of Social Studies emerged in a historic moment in which professionals in education have taken on critical pedagogy as their main dissent tool.
\end{abstract}

Keywords: Costa Rica, Social Studies, education, ideology, critical pedagogy 


\section{Introducción}

A mediados del 2018, la circulación de un ejercicio de evaluación relacionado con la materia de los estudios sociales ${ }^{23}$, que dicho sea de paso estaba mal planteado ${ }^{4}$, encendió voces de alarma entre algunos miembros de la clase política costarricense quienes aducían que el Ministerio de Educación Pública (MEP) estaba ideologizando a los estudiantes en favor del partido en el poder. La escaramuza sobre el tema se vio favorecida por un contexto en el que coincidieron, de un lado, el papel "agitador" asumido por los medios de comunicación, y del otro, las confrontaciones poselectorales aún vigentes entre el recién ascendido gobierno de Carlos Alvarado del Partido Acción Ciudadana (PAC) y los líderes opositores, en una Asamblea Legislativa fragmentada y dominada por la oposición.

Lo interesante es que la búsqueda en torno a ¿quién era responsable de la supuesta ideologización?, se desplazó rápidamente del ámbito educativo al político. Con mayor celeridad y efervescencia que la usada comúnmente para encarar los desafíos del país o los proyectos de ley, algunos diputados pidieron explicaciones al gobierno de turno sobre ese "grave" problema. Entre las acusaciones y la búsqueda de respuestas, de forma curiosa, cobraron protagonismo dos exministros de educación quienes se echaban las culpas mutuamente por haber impulsado programas educativos en esa materia escolar que, según sus propias lecturas, tendenciaban al estudiantado con posturas ideológicas que debían suprimirse. Lo que no se ventiló en los medios de comunicación fue que, más allá de la supuesta ideologización, y la búsqueda de sus responsables, la discusión derivó en un pulso político entre ambos exministros, ya que Sonia Marta Mora al inicio de su gestión (2014-2018) había derogado un plan de Estudios Sociales aprobado por Leonardo Garnier al final de la suya (2010-2014).

Pero como ocurre con casi todo en el "país más feliz del mundo", el conflicto se disipó, los litigantes enfundaron sus argumentos y el problema volvió al seno del MEP para que este tomase cartas en el asunto.

2 Semejante a lo que en otras partes de América Latina se denomina ciencias sociales o incluso, aunque menos preciso, enseñanza de la historia.

3 Si se revisa con cuidado el ítem en cuestión, fácilmente se llega a la conclusión de que cualquiera de las posibles respuestas debía ser tomada como válida.

4 Prueba aplicada a jóvenes de 17 años como requisito para finalizar la educación media y acceder a las universidades. 
El tema pasó varios meses en estado latente hasta que en 2019 se dio a conocer la sustitución de las pruebas nacionales de bachillerato ${ }^{5}$ por las denominadas pruebas para el Fortalecimiento de Aprendizajes para la Renovación de Oportunidades (más conocidas como pruebas FARO). En este caso, las autoridades del MEP señalaron que la materia de los Estudios Sociales no entraría en las pruebas de 2019, ya que no se ajustaba al perfil de una prueba por habilidades como la que se pretendía ${ }^{6}$. Sin embargo, parece claro que detrás de esta aparente inconveniencia estaba aún el tema político de fondo, que más allá de las pruebas invitaba a discutir sobre el papel de los Estudios Sociales.

Esta situación, de lamentables consecuencias para el sistema educativo costarricense, evidencia el escaso conocimiento que se tiene en el país, y particularmente en el seno de la clase política, sobre dos aspectos en concreto: la educación como aparato ideológico del Estado y el papel asignado a los Estudios Sociales como materia educativa. No vamos a entrar en los planteamientos de Althusser $(1988)^{7}$ (pues también habría que analizar a sus detractores) pero sí es importante recordar que la escuela constituye el principal aparato ideológico usado por el Estado para "dictar" lo que debe ser, lo que debe aprender y sobre lo que se espera de cada persona como ciudadano, en el marco de un modelo político específico. Arquetipo de ciudadano que se termina de moldear con la influencia de otros aparatos ideológicos como lo son la iglesia y la familia. En este sentido, cuestionarse si la educación desempeña algún rol ideológico es un ejercicio de poca trascendencia. Lo que resulta interesante indagar es si este aparato ideológico sigue como antes, al servicio del Estado, o si se ha vuelto en su contra y cuáles son las razones de este cambio.

No obstante, es preciso adelantar el criterio que se defiende en este trabajo y es que los Estudios Sociales por su misma naturaleza están llamados a jugar un importante papel de discusión ideológica. O,

5 En algún momento el mismo Ministro de Educación señaló que el MEP no contaba con la capacidad técnica para elaborar pruebas por habilidades y en consecuencia requería de presupuesto para consultorías.

6 Para profundizar en este tema puede verse, Althusser, L. (1988). Ideología y aparatos ideológicos del Estado. Freud y Lacan. Buenos Aires: Nueva Visión. La primera versión fue publicada en francés en 1970.

7 Parafraseando las ideas de Mainer, los intelectuales orgánicos (en la concepción Gramsciana) y con ellos algunos historiadores, son responsables de desvirtuar la enseñanza de la historia, en algunos casos presentándola como un "saber legítimo y legitimador, celoso guardián de los mitos originarios, que siempre es grato al poder". 
dicho de otra forma, es inconcebible que desde esta asignatura escolar no se desarrolle pensamiento crítico, lo cual implica necesariamente cuestionar la realidad, desde lo local o lo nacional. En esta línea Mainer $(1998$, p. 74) decía a finales del siglo pasado que, a pesar de ser una discusión de vieja data, seguía vigente -y lo sigue siendo hoy- la importancia de postular "no solo la incontestable importancia social e inmediatez sociopolítica del conocimiento histórico y sus usos, sino también la pertinencia de reflexionar (aunque sea una vez más) sobre la función social de la educación histórica de la ciudadanía en ciernes..."8.

\section{Ideología y educación: una añeja relación hegemónica}

La discusión sobre educación e ideología ha dado sustento a una gran cantidad de estudios que, haciendo eco unos de otros, indistintamente concluyen que la educación desempeña un activo rol desde el punto de vista ideológico. La diferencia entre ellos estriba en los niveles de profundidad con que hurgan en este papel y los objetivos con que lo hacen. En este sentido, mucha de la producción reciente descansa en los aportes de clásicos como Gramsci (1891-1937) sobre hegemonía, ideología y educación, así como de Apple (2008), McLaren (2005) y Giroux (2004) en sus escritos dirigidos especialmente a la pedagogía crítica.

Por ejemplo, Newland (1994) ${ }^{9}$ señalaba que el desarrollo educativo del siglo XX en los países latinoamericanos consolidó la idea del Estado docente al asumir el control y centralizar las políticas que antes estaban en manos de regiones o municipios, como fue el caso de Costa Rica desde el siglo XIX. De esta manera, el objetivo de tales modelos pretendía tomar al niño y transformarlo temprano, antes de que fuese contaminado con vicios sociales ${ }^{10}$. Evitar que el niño creciera entre "vicios sociales" escondía claramente una premisa de mayor peso para las élites y era la necesidad de homogenizar a la sociedad con base en un conjunto de ideales sobre lo que se debía hacer para transitar de la barbarie al progreso. En el inter texto de esta idea, ampliamente extendida por Latinoamérica, y apoyada por las corrientes positivistas, no

8 Newland es Máster of Letters en Historia por la Universidad de Oxford y Dr. Litt. en Historia de la Universidad de Leiden.

9 Traducción libre hecha por el autor del presente ensayo de: "taking the child and transforming him early, before he could be contaminated by social vices" (Newland, 1994, p. 454).

10 Traducción libre hecha por el autor del presente ensayo de: "The most noteworthy characteristic of teaching content was the surge of nationalism that permeated all classes, promoting the celebration of national history..." (Newland, 1994, p. 466). 
solo la heterogeneidad ideológica era perjudicial para el Estado, sino que incluso la diversidad cultural era un aspecto que se debía combatir para lograr una mayor cohesión social (Newland, 1994); aspecto que indudablemente resultó más fácil en países como Costa Rica, contrario a aquellos con formas de gobierno federal, con fuertes regionalismos o con abundante población indígena.

Parte de ese proyecto de cohesión incluía la invisibilización de cualquier postura que riñese con la visión de una historia oficial pensada y diseñada desde la cúpula política y desde la burocracia que se consolidó como otro grupo poderoso. Tanto así que, según Newland (1994), la característica más notable de la enseñanza fue el surgimiento del nacionalismo que impregnó todas las clases, promoviendo la celebración de la historia nacional" . Pero no está demás señalar que esa "historia nacional" o ese nacionalismo respondía igualmente a un modelo de Estado liberal en el que se intentaba definir un sentimiento de pertenencia o "identidad"; en nuestro caso la "identidad costarricense". La pregunta es ¿quién la construye o cuáles son sus elementos constitutivos? Estas preguntas, aunque parezcan triviales en realidad no lo son, pues, más allá de la discusión sobre identidad versus identidades o de "identidades culturales", existen al menos dos ámbitos de la identidad que es preciso puntualizar. Como lo explica Rachik (2006, p. 9), "Frente a la identidad colectiva blanda, basada en ideas imprecisas y asumida por una categoría social de contornos difusos, cabe oponer la identidad colectiva dura asumida por un grupo social estructurado cuya élite produce y difunde una ideología sistemática". La primera retrata claramente la "fragilidad" de la identidad colectiva en sociedades expuestas a procesos migratorios y a profundas situaciones de desigualdad y vulnerabilidad, mientras que el segundo tipo es consistente con la lógica discursiva que se teje desde entornos cohesionados con base en una afinidad sociopolítica, como en este caso serían los partidos políticos y sus clases dirigentes.

Ahora bien, la posibilidad de impulsar una estrategia que logre consolidar y extender esa identidad dura al resto de la sociedad, reside en un uso inteligente de su poder hegemónico y en el papel de los intelectuales orgánicos en el sentido gramsciano del término. Siguiendo este rumbo, Jarpa (2015, p. 125) en uno de sus ensayos señala que en el pensamiento de Gramsci

11 Es necesario acotar que esta lectura se hace desde una concepción socio-política y no curricular. 
uno de los elementos clave para comprender la hegemonía es que ella requiere de estrategias que oculten la intención explícita de la clase dominante de dirigir política, intelectual y moralmente a la clase dominada, propiciando la naturalización de esta forma de explotación a través del «consenso manipulado».

El éxito de esa "naturalización" del proceso hegemónico, pareciera explicarse en parte por el disfraz de igualdad, tolerancia, respeto y otros valores enarbolados por los discursos democráticos de moda en las sociedades occidentales y en la nuestra en particular. Como ejemplos de esa identidad dura y "naturalizada" desde el sistema educativo basta con enunciar, para el caso costarricense, las celebraciones del 7 de noviembre como Día de la Democracia y el 11 de abril la Batalla de Rivas en el contexto de la Campaña Nacional de 1856-1857. El primero de ellos se presenta como ícono o hito del valor intrínseco asignado a los procesos electorales como medio de expresar nuestra libertad, derechos y ciudadanía, incluso al distanciar la realidad costarricense de otras centroamericanas y latinoamericanas. El segundo, que más que la batalla exalta al héroe Juan Santamaría, establece los rasgos distintivos del patriotismo y sacrificio que se espera del costarricense. Y no casualmente ambas fechas forman parte de las celebraciones o efemérides que los centros educativos deben acatar, año tras año.

En forma similar a ese "manejo educativo" de la historia nacional, la élite que comparte esa "identidad dura" ha creado discursos y escenarios con los que disfraza el control hegemónico que ejerce sobre la economía, la política y la misma educación. Y aunque algunos de estos discursos forman parte de los contenidos que se llevan a las aulas, su análisis está mediado por una serie de aspectos entre los que sobresale no solo el rol del docente como intelectual, sino el hecho de que "la relación pedagógica es una relación de hegemonía" (Jarpa, 2015, p. 130). En este sentido, basta con examinar la estructura organizativa de los planes del estudio del MEP para darse cuenta de que en ellos se establecen con rigor los contenidos y la forma de evaluarlos, pero estratégicamente también se consituye lo que se ha dado en llamar contenidos procedimentales y actitudinales, desde los cuales se guía al docente para cumplir los "objetivos esperados"'2. Así, en los planes

12 La primera edición (en inglés) es de 1979. 
de estudio, este propósito homogenizante se presenta bajo el supuesto de ofrecer un "plan integrado". Este conglomerado de acciones pedagógicas, así como de valores por desarrollar en los estudiantes, refleja, en última instancia, un "currículo blindado" ante cualquier iniciativa docente de carácter crítico o transgresor.

El complemento ideal para controlar este tránsito por los contenidos "socialmente pertinentes" y evitar que los docentes se dispersen o que distorsionen el proceso con sus "currículos ocultos", ha estado en la ejecución de pruebas nacionales estandarizadas. Hasta hace unos pocos años, además del bachillerato, estas también se aplicaban en el sexto año de primaria (a los 11-12 años de edad) y en noveno de secundaria (entre los 14 y 15 años de edad). Claramente, es el mismo Estado, desde las instancias ministeriales quien define los contenidos que serán sujetos de evaluación, así como los indicadores esperados para tales pruebas, lo cual es refrendado por el Consejo Superior de Educación. El paso de los exámenes de bachillerato a las denominadas pruebas FARO busca evaluar habilidades más que contenidos; sin embargo, aún no existen resultados y por ello el debate sobre su pertinencia y aplicación deberá esperar a otro momento.

Si se parte de las lógicas expuestas, resulta claro que el sistema educativo costarricense ha desempeñado un activo papel ideológico (aunque difícil de estimar), pero donde también han aflorado corrientes críticas, contraculturales o desideologizantes, en parte gracias al papel de las universidades como formadoras de formadores. Sobre este particular, y al volver a los argumentos de Jarpa (2015, p. 128), es claro que está en manos de los intelectuales "contribuir al mantenimiento del sistema ideológico dominante o participar de un proyecto de disenso y cuestionamiento del sistema establecido...". Pero, además, si se acepta que la ideología es una "concepción de mundo" sustentada en un conjunto de valores y normas, tanto individuales como colectivas (Jarpa, 2015), es fácilmente comprensible entender que esta se transforme, en cuyo caso podrían darse distanciamientos o pérdida de cohesión a lo interno del grupo dominante. Este proceso daría lugar a lo que Hoogerwerf (1969) desde finales de la década de 1960 llamaba desideologización o empobrecimiento de la ideología en un estudio que analizaba el caso europeo.

En consonancia con los argumentos de dicho autor, una ideología se deteriora por pérdida de su coherencia interna, por distanciamiento 
entre sus elementos objetivos y subjetivos y por desintegración de la agrupación que la sostiene (Hoogerwerf, 1969). La pregunta es si ¿las construcciones ideológicas sostenidas por el bipartidismo durante la segunda mitad del siglo XX en Costa Rica se han mantenido o han experimentado cambios? Aunque es claro que la aparición de nuevas opciones en la arena política costarricense ha impulsado una fragmentación importante de la masa electoral, es fundamental también visualizar las transformaciones operadas en las agrupaciones políticas. Como ejemplo concreto, puede citarse el cambio de rumbo impulsado por el Partido Liberación Nacional (PLN) desde mediados de la década de 1980. Según Gudmundson (2018) tal cambio sería el responsable de la división interna de esta agrupación y la reagrupación de algunos de ellos en torno al PAC que llegó al poder por primera vez en el periodo 2014-2018 y que repitió para el periodo 2018-2021, al inicio del cual surgió la problemática sobre la ideologización de los Estudios Sociales descrita en la introducción de este trabajo.

A partir de los argumentos expuestos, es ineludible plantear si estas preocupaciones por la ideologización de los estudiantes responden realmente al hecho de que se favorece abiertamente a un partido político, o más bien a una situación de crítica sobre el desarrollo sociopolítico costarricense ahora de la mano de profesionales que han asumido el disenso como estrategia de lucha para buscar una transformación profunda de la sociedad. En el siguiente apartado, se intentará dar respuesta a esta pregunta mediante un análisis de la influencia del Estado en la "ideologización" de los estudiantes que rastree indicadores en los planes de estudio, así como del papel de los docentes, visto desde una tipología que es fácilmente identificable en Costa Rica.

Aunque este artículo no tiene como objetivo hacer una disertación teórica de los elementos ideológicos de la educación, antes de pasar al siguiente apartado es importante rescatar algunos aportes de autores que han analizado el papel ideológico de la educación como Apple (2008) en su obra Ideología y currículum ${ }^{13}$, y McLaren (2005) en La vida en las escuelas: Una introducción a la pedagogía crítica en los fundamentos de la educación. El primero de ellos tiene claro que el desarrollo de la ideología, de la hegemonía y el proceso selectivo de contenidos para el currículum constituyen la base que cimenta la

13 El destacado es del original. 
reproducción del orden establecido. Al seguir la línea trazada por "sociólogos del currículo", particularmente británicos, Apple señala que las escuelas

en cuanto que instituciones, no sólo son unas de las principales agencias de distribución de una cultura dominante efectiva; junto con otras instituciones, y aquí cobran mucha fuerza algunas de las interpretaciones económicas, ayudan a crear personas (con los valores y significados apropiados) que no ven otra posibilidad seria que el conjunto económico y cultural ahora existente. (2008, p. 17)

En esta acción de moldear a la sociedad y de presentar la realidad como "algo dado", es de suma relevancia cuestionar tanto el cuerpo de conocimientos seleccionados para el currículo como al grupo encargado de esta labor. Develar estas relaciones permitirá acceder a una "valoración más concreta de las vinculaciones existentes entre el poder económico y político y el conocimiento puesto a disposición (y el no puesto a disposición) de los estudiantes" (Apple, 2008, p. 18) ${ }^{14}$. Esta advertencia es sin duda reveladora pues muchas veces se analiza el currículo desde lo que dice, pero poco se investiga acerca de lo que no dice, $o$, dicho de otra manera, sobre lo que intencionalmente se sustrae de los conocimientos que la élite considera necesarios o pertinentes para una juventud en formación, en un momento determinado. Esto también ocurre, según sus palabras, porque no pocos profesores obvian el papel político de la educación al punto que la despolitizan completamente (Apple, 2008) y así se constituyen en simples transmisores de la ideología dominante ${ }^{15}$.

Ante este panorama, el desarrollo de una conciencia crítica, y especialmente de una acción crítica, presupone un paso fundamental en el camino de la transformación social. En congruencia con este fin, como dice Apple, es imperativo tener claro que las escuelas

14 Para profundizar en esto Apple (2008) recomienda revisar los trabajos de Michael F. D. Young, Knowledge and Control; Richard Brown, Knowledge, Education and Cultural Change; Basil Bernstein, Class, Codes and Control (volume 3: Towards a Theory of Educational Transmissions); Michael Flude y John Ahier, Educability, Schools and Ideology; y el de Rachel Sharp y Anthony Green, Education and Social Control.

15 La primera versión en español se publicó en 1984. 
están tan entrelazadas con otras instituciones políticas y económicas de las que dominan la colectividad, y puesto que las escuelas suelen actuar sin cuestionamientos distribuyendo conocimiento y valores, por medio del currículo explícito y oculto, que suelen actuar como apoyo de esas mismas instituciones, es necesario que los educadores se comprometan en el análisis de búsqueda de los modos en que trabajan inconscientemente con esos valores y compromisos. (2008, p. 168)

Quizás la forma de develar ese manejo ideológico con que el Estado intenta que los profesores asuman su trabajo, reside en reconocer el contenido político de la educación. McLaren (2005, p.74) hace una aportación sustantiva al señalar como su premisa "que todos los pensamientos, actos y relaciones son políticos en un sentido ideológico"16. Pero lo que resulta más impresionante es la claridad con que este autor veía el cambio sociopolítico a mediados de la década de 1980 -que no se diferencia del actual- al decir

En esta era de amnesia histórica, de esperanzas pospuestas indefinidamente y de un alejamiento de los derechos civiles, los conceptos de lucha social y de valor cívico se han congelado alrededor de formas de humanismo liberal políticamente acomodaticias y de un cambio ideológico hacia la Nueva Derecha y la agenda política neoliberal. Mientras los pilares de nuestro templo democrático se tambalean con los actuales vientos reaccionarios, no podemos más que ver un futuro incierto a través de las grietas de la historia. (McLaren, 2005, pp. 80-81)

En este punto es necesario rescatar que el papel de los Estudios Sociales reside de forma precisa, y fundamentalmente, en su capacidad para ver "a través de las grietas de la historia" y analizar desde ellas el devenir de la sociedad en sus distintos ámbitos. Esto significa que sobre el docente recae la enorme responsabilidad, pero también la oportunidad pedagógica, de resignificar el sentido de la historia en el salón de clases y darle un uso eficaz que permita el empoderamiento

16 Este argumento fue originalmente abordado por McLaren en un artículo titulado "Revolutionary pedagogy in post-revolutionary times: Rethinking the political economy of critical education”, en 1998. 
de los jóvenes de tal manera que, al salir del aula, el "mundo exterior" no sea un monstruo que los individualice o los cosifique como simples engranajes de un sistema dentro del cual todo parece "normal" o excepcionalmente transformable. Este reto pasa por reconocer, como lo señala Giroux (2004, p. 72), que para entender mejor el proceso de escolarización se debe tener presente tres aspectos

1. Las escuelas no pueden ser analizadas como instituciones separadas del contexto socioeconómico en el que están situadas.

2. Las escuelas son sitios políticos involucrados en la construcción y control de discurso, significado y subjetividades.

3. Los valores del sentido común y las creencias que guían y estructuran las prácticas en el salón de clase, no son universales $a$ priori, sino que son construcciones sociales basadas en supuestos normativos y políticos específicos.

Este repaso, claramente insuficiente para agotar el tema, y quizás para muchos, alejado de las interpretaciones polémicas que existen sobre algunas de esas posturas por su cercanía a los enfoques marxistas, pretende al menos sentar una línea base de interpretación para comprender la relación entre educación e ideología. La pedagogía crítica particularmente resulta un paradigma que, aunque el mismo McLaren $(2005, \text { p. } 74)^{17}$ decía que "ha sido esterilizada, vulgarizada, domesticada y purgada de su profundidad teórica y discernimiento" sigue constituyendo el prisma más efectivo con que cuenta la escuela de hoy, y en especial los Estudios Sociales, para cumplir con su papel educativo y su responsabilidad histórica.

\section{Estudios Sociales: profesorado e ideología}

En el caso de Costa Rica, puede entenderse, desde el concepto de Estado docente expuesto en el apartado anterior, como las escuelas normales jugaron un papel central en la formación de maestros y maestras, hasta la creación de la Universidad de Costa Rica (UCR) en la década de 1940. Así, el magisterio emprendido en todo el proceso de expansión de la educación costarricense estuvo definido desde el gobierno y consolidado sobre la base de planes de estudio "diseñados

17 La UNA absorbió a la Escuela Normal de Heredia que se había creado en 1968. 
a la medida" para una sociedad patriarcal y agrícola, donde una élite oligárquica ligada al cultivo del café se afianzaba cada vez más en el poder. Sin lugar a duda, la creación de la UCR y más tarde la Universidad Nacional (UNA) ${ }^{18}$ constituyeron un punto de quiebre respecto al papel hegemónico del Estado sobre la educación, entre otras cosas por la especialización paulatina de los cuadros académicos.

Al tener esto como telón de fondo, hablar del papel de los Estudios Sociales en el marco de una sociedad democrática como la costarricense es de suma relevancia y resulta de utilidad para los fines de este trabajo reconocer algunas de las interpretaciones que se han hecho sobre este tema. Así, por ejemplo, como lo han expresado algunos estudios (Salas, 2000; Agüero, Araya, Marín, Molina y Rojas, 2011), antes de 1951 la enseñanza de Historia, Geografía y Educación Cívica se realizaba de manera segmentada y enfrentaba serios problemas, entre ellos la formación de profesores. Y aunque esta situación se resolvió parcialmente con la creación de la UCR y la titulación de docentes, de acuerdo con Solano (2006), según se cita en Agüero et al., (2011, pp. 28-29),

ni los contenidos ni el enfoque pedagógico respondieron al modelo de desarrollo impulsado por el Estado. En este sentido, los Estudios Sociales se constituyeron en un "excelente artificio socio-político para transmitir, mediante el sistema educativo, los principios y aspiraciones del modelo político y material de la recién declarada Segunda República ${ }^{19}$.

Asimismo, desde su inclusión como materia escolar en el currículo nacional, se apostó porque este fuese un campo de encuentro de distintas disciplinas. Citando a Salas (2000, p. 57), indica que para entonces se señalaba que los Estudios Sociales en la educación secundaria debían traducirse "en el logro sistemático de la comprensión del patrimonio cultural, de la apreciación de valores de la sociedad democrática, y de la afirmación de los ideales que inspiran la convivencia humana". En aparente consonancia con ese objetivo de los Estudios Sociales, el

18 En 1948 Costa Rica vive un conflicto armado y como resultado de este el bando que se impuso decretó la formación de la Segunda República.

19 El artículo 77 de la Constitución indica que "la educación pública será organizada como un proceso integral correlacionado en sus diversos ciclos, desde la pre-escolar hasta la universitaria. 
artículo 24 de la Ley Fundamental de Educación (Ley 2160), aprobada en 1957, establecía que la formación de docentes debía

a. Inspirarse en los principios democráticos que fundamentan la vida institucional del país, y en lo que establece el Artículo 77 de la Constitución Política ${ }^{20}$;

b. Asegurar al educador una cultura general y profesional y los conocimientos especiales necesarios para el buen servicio docente;

c. Promover en el educador la formación de un genuino sentimiento de los valores de la nacionalidad, el aprecio de los valores universales y la comprensión de la trascendencia de su misión.

Está claro que el afán por fortalecer la historia nacional, los valores de la sociedad democrática y el sentido de identidad resultaban elementos centrales del papel asignado a la educación y a los Estudios Sociales de forma especial. Sin embargo, pareciera que estos propósitos empezaron a sufrir contratiempos tempranamente pues como lo indican Soto y Herrera (1998) en su tesis de licenciatura en Estudios Sociales, según se citan en Agüero, et al. (2011, p. 29), para 1958 el Estado se vio en la necesidad de impulsar una reforma a los recién creados Estudios Sociales,

pues los cambios sociales, políticos y económicos vividos en ese momento histórico, suponían nuevos retos, los cuales sólo serían superados si se lograba una nueva educación fundamentada en las acciones y actitudes que se reforzaban claramente con la inclusión del modelo de la escuela activa en Costa Rica. En consecuencia, la educación media se modificó para estar a la altura de las necesidades intelectuales y vocacionales que operaron con el modelo de Sustitución de Importaciones, que reforzaban hábitos necesarios para desenvolverse en una empresa; no pudo el docente negarse a las nuevas condiciones del sistema educativo, el cual se ampliaba con la presencia y exigencia de nuevos grupos sociales.

20 Un aspecto importante que señala Ovares es que en la estructura de ODECA estaba el Departamento de Asuntos Culturales y Educativos, al cual estaba adscrita una oficina denominada Centro Regional de Libros de Texto para Centroamérica y Panamá, financiado por la Alianza para el Progreso mediante la ROCAP. Después de 1971 dicho centro pasó a llamarse Instituto Centroamericano de Libros de Texto (ICALT). 
En 1964, entró en ejecución una nueva reforma educativa pero como lo señala Salas (2000, p. 59) en cuanto a los contenidos "no hubo ninguna integración en ejes temáticos que contribuyera a fomentar la enseñanza y el aprendizaje desde una perspectiva interdisciplinaria, tal y como se expresaba en la misión y los objetivos de la materia". Dicho de otra manera, la reforma no logró modificar el modelo de enseñanza que se arrastraba desde la primera mitad del siglo XX, y contrario a ello se reforzó una tendencia a integrar cada vez más contenidos en la materia. Ante este panorama, y con la incorporación más tarde de las pruebas de control de calidad, los docentes "buscaron formas más expeditas de entrega y memorización de información" (Salas, 2000, p. 60). En un escenario educativo como ese, no es de extrañar entonces que la reproducción de contenidos ideológicos emanados de la clase política y de la élite hegemónica se llevaran a las aulas sin intermediación alguna de un espíritu crítico.

Por ello, cuando en 1971 se crea el Plan Nacional de Desarrollo Educativo, entre los fines esenciales se hablaba de "elevar el nivel educativo promedio de la población, particularmente en las zonas hasta esa fecha menos favorecidas, a fin de conseguir la integración nacional" (OEI, 1997, p. 5). Pero especial mención demanda el objetivo de "Modernizar el sistema educativo para que responda a las necesidades sociales y económicas del país y favorezca el proceso de desarrollo" (OEI, 1997, p. 5). Como puede verse, estas inquietudes resultan semejantes a las que motivaron la reforma de 1958 según lo expuesto por Soto y Herrera en su tesis (1998). Pero, además, según Retana (2010, p. 22) en su trabajo Currículo de la Educación Media Costarricense de 1950 a 2010, escrito para el Tercer Informe del Estado de la Educación, la reforma de 1971 respondía de manera general a las ideas "desarrollistas del momento (...) que concibieron a la educación como uno de los factores del desarrollo económico y social de los países y al educador como agente de cambio social". Ejemplos como estos sirven de base para entender el desarrollo de los Estudios Sociales, al menos en lo que podría llamarse su etapa de consolidación como materia escolar entre 1951 y 1970. A partir de aquí, haremos un recorrido breve por los planteamientos de algunos de los programas del MEP emitidos desde la década de 1970. 


\section{Ideología en los Estudios Sociales: casos concretos}

En este apartado, no se intenta hacer un análisis exhaustivo de lo planteado en los programas de estudio del MEP, pero si rescatar ejemplos que sirvan como muestra para evidenciar el rol ideológico de la materia de los Estudios Sociales, al menos desde la década de 1970. Se parte de esta década debido a los cambios experimentados en la organización del sistema educativo (desde 1964), la creación de programas específicos y la puesta en marcha del Plan Nacional de Desarrollo Educativo de 1971. Sin embargo, antes de entrar al análisis concreto de los programas de estudio es importante rescatar primero que, desde 1962, ya existía un convenio centroamericano firmado por los Ministros de Educación mediante el cual se le encargaba a la Organización de Estados Centroamericanos (ODECA) la tarea de unificar la educación primaria de la región. Este convenio respondía claramente al contexto de la creación del Mercado Común Centroamericano (MCCA) en 1960.

Se rememora este convenio porque en el marco de su aplicación la ODECA, en coordinación con la Agencia para el Desarrollo Internacional (AID) mediante su Oficina Regional para Centroamérica y Panamá (ROCAP), elaboraron una serie de libros de texto para la educación pública centroamericana. Estos cubrían materias como Lectura, Matemática, Ciencias y Estudios Sociales. En 1967 la Academia Costarricense de la Lengua, ante solicitud del Ministro de Educación, realizó un estudio de los libros de Lectura y se pronunció en contra por considerarlos inapropiados para la realidad nacional (Academia Costarricense de la Lengua, 1967). Sin embargo, todo indica que, pese a las críticas, algunos de estos libros se siguieron utilizando en la educación costarricense y, aunque no existe evidencia que permita valorar su difusión, es valioso al menos citar un estudio de Ovares (1977) bajo el título Educación como integración ideológica. Lectura crítica de los textos ODECA-ROCAP ${ }^{21}$.

En ese trabajo, centrado en los libros de Lectura y de Estudios Sociales de 1 a 4 año de educación primaria, Ovares (1977) habla de cómo se "recortaban" contenidos para moldear un perfil educativo. Esa lectura, aunque hecha desde un paradigma marxista, aporta algunas ideas respecto a lo que se intentaba hacer desde ODECA en las décadas

21 Utilizamos el programa de I, II y III ciclo de la Educación General Básica. Niños y jóvenes de entre 6 y $14-15$ años. 
de 1960 y 1970. De las conclusiones de Ovares (1977) interesa rescatar que según ella

se omite cualquier mención a la existencia de las clases sociales y de la lucha de clases: la familia, la escuela y la sociedad en general progresan bajo el signo de la cooperación y la ayuda mutua. El trabajo, alejado de su contexto, es fuente de riqueza y alegría para todos (pp. 146-147). Las representaciones obtenidas por medio de esos recortes nos presentan una visión idílica de la sociedad. A nivel ideológico la burguesía crea la ilusión de integración, de sociedad en vías de perfeccionamiento, de conciliación de clases (p. 148). Los problemas que no logra ocultar están «en vías de resolverse», gracias a una cierta energía interior del sistema que se personifica en el Estado, las instituciones y la cooperación de todos. (149)

Ahora bien, si se vuelve al propósito concreto de este apartado, se inicia el análisis de programas de estudio con el de $1971^{22}$. Lo primero que se advierte al analizar el ese programa es que se trata de una propuesta "blindada" contra cualquier desavenencia o transgresión por parte de los maestros y profesores, ya que en ella se establecían no solo los contenidos que se debía impartir, sino también las pautas de lo que se debía profundizar y aquello que no se debía "tocar". Por ejemplo, al abordar el tema de la producción de banano y el papel de la United Fruit Company (UFCo), se indicaba claramente "no entrar en el análisis de los contratos". Esta limitación claramente impedía que los estudiantes conociesen a profundidad los derechos que el Estado había cedido a la compañía estadounidense, entre ellos la entrega de gran cantidad de tierras. Esto no era políticamente correcto discutirlo en la década de 1970, cuando el mismo Gobierno hablaba de la necesidad de una reforma agraria.

El programa de I, II y III ciclo reforzaba una concepción educativa centrada en el desarrollo de habilidades y destrezas, hábitos y actitudes orientados al aprecio de la cultura local y regional, así como al fortalecimiento de valores identificados como parte de la forma de vida democrática, entre ellos tolerancia, responsabilidad, paz, diálogo, etc. En forma más específica abordaba hábitos relacionados con el "hablar

22 La mayoría de estos personajes son ex presidentes de Costa Rica. 
con tono de voz adecuado" y cuidar la apariencia personal (MEP, 1971). Dicho de manera más concreta, este programa se asemeja a "una receta" que buscaba la formación de ciudadanos "a la medida". Quizás la única razón que justificaba esta ultra demarcación del ejercicio docente por parte del Estado -más allá de sus intereses políticos e ideológicosera que la formación de docentes en Estudios Sociales apenas iniciaba en la UCR y la UNA se crearía hasta en 1973.

$\mathrm{Al}$ revisar los objetivos generales de la asignatura de Estudios Sociales para los tres ciclos mencionados, destaca entre ellos el que invitaba a "Fomentar en el educando el aprecio por la herencia cultural con fidelidad inteligente a los ideales costarricenses y participación activa en las prácticas democráticas" (MEP, 1971, p. 3). Tal objetivo no es, en sí mismo, motivo de preocupación pues cualquier Estado se consolida sobre la base de un ideario, $\mathrm{y}$, es más, lo requiere en tanto proyecto de Estado-Nación. Sin embargo, las diferencias afloran en tanto la perspectiva analítica sobre la historia nacional abre paso para que el dogmatismo político se apropie de los contenidos a enseñar y establezca, a partir de ellos, una especie de "historia oficial". Esta inquietud queda claramente develada en la presentación del plan de contenidos para el III ciclo de la Educación General Básica (1971, p. 1) cuando se propone como objetivo de la enseñanza "Despertar y vitalizar un sentimiento de admiración y gratitud hacia aquellos hombres e instituciones que, a través de los tiempos, han ido forjando nuestra situación actual". En consonancia con ese objetivo, el abordaje que se sugería para hablar del desarrollo costarricense de los siglos XIX y XX -hasta 1971 en ese entonces- era el de analizar a los personajes más destacados y sus obras de gobierno. Así se proponía estudiar las obras de figuras como Juan Mora Fernández, Braulio Carrillo, José María Castro Madriz, Juan Mora Porras, Jesús Jiménez, Julián Volio (por su trabajo en lo educativo), Cleto González Víquez, Ricardo Jiménez y Calderón Guardia (este último con especial hincapié en las reformas sociales de la década de $1940)^{23}$. Estos contenidos estaban asimismo conectados con el objetivo de "Promover una efectiva formación ciudadana y reforzar así el sentimiento democrático" (MEP, 1971, p. 2). No está demás señalar que el estudio de los presidentes y sus acciones se mantuvo en el currículum de Estudios Sociales al menos hasta la década de 1990.

23 Ese contenido correspondía a la unidad 7 de séptimo año. 
Sin embargo, resulta aún más revelador, desde el punto de vista ideológico, algunas propuestas de aquel plan de estudios para trabajar una sección del III ciclo denominada "Bosquejo de la realidad socio-política, económica y cultural costarricense" ${ }^{24}$. Entre las sugerencias de trabajo -de lo económico- se proponía que al ver el surgimiento de las primeras fortunas ligadas al café y a las haciendas, se analizara estas en el marco de la aparición de una marcada distinción social de estos grupos -nótese que se omitía la idea de desigualdad-, y además sugería conectar esa realidad con sus beneficios ya que "La existencia de divisas trajo como consecuencia: caminos, planteles educativos, libros, etc. El Teatro Nacional" (MEP, 1971, p. 13). De alguna manera, la desigualdad social originada en torno a la caficultura, como concentración de tierras, proletarización, etc., debía ser presentada desde su "lado positivo" si se me permite usar este eufemismo.

Para finalizar con el programa de 1971, se ha reservado lo que quizás resulte el ejemplo más claro de lo que el Estado quería con la educación de ese momento y que de paso dio motivo para el título de este trabajo. Siempre en relación con ese "bosquejo" de la realidad costarricense, una de las sugerencias para abordar el "Factor social" señalaba lo siguiente: "Sociedad costarricense: aunque existan desigualdades socio-económicas-culturales, resaltar la atenuación de éstas gracias al sentimiento democrático y a la relativa pobreza general de nuestro país" (MEP, 1971, p. 14) ${ }^{25}$. Este enunciado reproduce a la perfección lo que en Costa Rica se denominó "modelo nacional democrático y rural igualitario" más conocido como el mito de la democracia rural impulsado en Costa Rica desde los estudios de autores como Rodrigo Facio Brenes, Eugenio Rodríguez Vega y, en forma particular, por Carlos Monge Alfaro ${ }^{26}$. Según este mito, la democracia costarricense estaba cimentada en el igualitarismo heredado de la colonia, el cual a su vez se explicaba por la pobreza y el aislamiento de la provincia de Costa Rica con respecto a la Capitanía General de Guatemala, lo cual implicaba que hasta los colonos españoles debían trabajar la tierra. Este mito, sin embargo, fue desestructurado por el historiador Gudmundson (1990) en su trabajo "Costa Rica antes del café" hacia finales de la década de

24 El destacado no es del original.

25 Todos ellos vinculados al Centro para el Estudio de los Problemas Nacionales, semillero ideológico de lo que posteriormente sería el Partido Liberación Nacional.

26 La primera edición en inglés se publicó en 1986 y la primera versión en español es de 1990. 
$1980^{27}$. No obstante, lo importante de rescatar es que desde el MEP se intentaba disfrazar las desigualdades sociales y económicas que vivía la población con un discurso de sacrificio casi monástico, cimentado en la idea de que, en un país pobre como este, lo "normal" era ser pobre.

El programa de Estudios Sociales para el III ciclo de 1978 es otro caso que aporta ejemplos claros sobre la forma en que se les presentaba el mundo a los jóvenes. Por ejemplo, en noveno año al analizar los conflictos sociales que afectaban al mundo de entonces, el enfoque se centraba en la subalimentación, analfabetismo, contaminación y los problemas urbanos, de tal forma que las causas de estas problemáticas se alejaban de la administración del Estado y de las desigualdades introducidas por los juegos del mercado o de las deficiencias del modelo de desarrollo (MEP, 1978a). En este sentido, no se exponía por ejemplo que el modelo de desarrollo "hacia adentro" -más conocido como sustitución de importaciones- demostraba serias dificultades en la mayor parte de América Latina y que su sostenimiento, de manera fundamental en el caso costarricense, fue posible gracias al desarrollo del agro, el cual además recibía cada vez menos atención por parte del Estado.

Pero es más sobresaliente, desde el punto de vista ideológico, un contenido del programa de sétimo año titulado "Costa Rica isla democrática en el istmo", para cuyo abordaje se proponía como actividad central "Comente el significado de la siguiente frase: En Costa Rica hay más maestros que soldados" (MEP, 1978a, p. 30). Esta diferenciación, ligada al mito de la Suiza Centroamericana, claramente se establecía en un período donde los conflictos armados y las dictaduras hacían eco en América Latina y en Centroamérica en particular, como el caso de Somoza en Nicaragua. Así, la carga ideológica de representar a Costa Rica como un país pacífico y sin ejército ${ }^{28}$ se consolidó en los distintos planes de estudio, con el fin de crear una distinción entre Costa Rica y el resto de Centroamérica. Así, por ejemplo, en sétimo año cuando se proponía "valorar la necesidad de fomentar el progreso y el desarrollo nacional" la actividad indicada para los docentes era discutir la frase "lo nuestro es mejor porque es nuestro" (MEP, 1978a, p. 29). Estas distinciones, sin embargo; fueron más allá de lo educativo y han servido a los gobiernos de turno para señalar sus logros -indudablemente

27 El ejército fue abolido como institución en diciembre de 1948 como parte de las acciones impulsadas por José Figueres Ferrer al frente de la Junta Fundadora de la Segunda República.

28 El destacado no es del original. 
importantes- y para reafirmar la idea de excepcionalidad detrás de la cual se esconde la premisa de que la sociedad debe estar en sintonía con el gobierno, apoyando su accionar, en lugar de combatirlo o de cuestionar su política económica o social.

Ese argumento resulta congruente con la fundamentación que se establece en el programa de Estudios Sociales para décimo año en 1978. En él se indicaba que Estudios Sociales se fundamentaba "en la doctrina democrática" y la "solidaridad humana", pero además dejaba claro que "En tal virtud, con él se cultivan sentimientos y actitudes de lealtad a las instituciones lo mismo que a los principios e ideales que enriquecen la vida colectiva" (MEP, 1978b, p. 1). Este supuesto, unido al enfoque personalista utilizado para examinar la historia nacional llevaban a pedir como actividad sobre el tema de la democracia costarricense, por ejemplo, "Preparar informes sobre los personajes de la historia nacional que han fortalecido la democracia costarricense" (MEP, 1978b, p. 4). Aunque el plan no permite asegurarlo, es plausible que estos personajes eran en su mayoría hombres, pues en todo el programa de ese año la presencia femenina es poco menos que invisible. Aspectos como este son reveladores respecto al tipo de sociedad que se impulsaba y especialmente sobre la noción liberal-patriarcal imperante en ese momento. Pero se adicionan contenidos como "derechos y deberes del costarricense" y, de manera esencial, "instituciones democráticas de Costa Rica" se hacían desde criterios de reafirmación. Prueba de esto es que no existe ni una sola orientación para discutir, por ejemplo, debilidades o formas de mejorar dichas instituciones.

En 1979, el MEP crea otro plan de Estudios Sociales para décimo año denominado "Curso opcional y básico". En este programa y sobre la idea de la educación activa, se indicaba que

Los Estudios Sociales, entre otras cosas, procuran al alumno la oportunidad de adquirir un mayor caudal de experiencias para aplicarlas a situaciones que ofrece la sociedad en su continua evolución cultural. Esta información recobra mayor veracidad aún, si tiene en cuenta que el moderno concepto de los Estudios Sociales pone énfasis en el hombre como ser activo e inteligente, creador de cultura, y sobre las manifestaciones políticas, 
sociales, económicas, artísticas, religiosas, éticas y jurídicas de las sociedades humanas. (MEP, 1979, p. 2$)^{29}$

Esta noción de Estudios Sociales -con un fuerte sesgo de lo que hoy denominamos educación cívica o formación ciudadana- presentaba sin duda un interesante cambio respecto a los programas anteriores pues de alguna forma señalaba la importancia de comprender la sociedad humana más allá del concepto oficial de patriotismo o de historia nacional. Sin embargo, el enfoque del programa centrado en Historia Universal de los siglos XVIII, XIX y XX dejó poco espacio para analizar la realidad costarricense de manera que lo único que se indica puntualmente era "Discutir los problemas y logros del desarrollo de Costa Rica" (MEP, 1979, p. 8). Lo interesante es que este tema está inserto en el eje de contenidos dedicado a "El tercer mundo" pero el énfasis asignado al caso costarricense es el de logros del desarrollo, de nuevo casi como una excepcionalidad. Por otra parte, en los objetivos generales sobre manejo de contenidos se establecía la indicación de "Aprovechar todas las oportunidades para comprender los principios básicos de la democracia frente a otras ideologías" (MEP, 1979, p. 3). Reforzar este aspecto era esencial en un contexto donde los efectos de la crisis de los hidrocarburos iniciada en 1973 empezaban a ser insostenibles en Costa Rica y existía el peligro de que resurgieran los viejos fantasmas -el comunismo- que se combatieron en la década de 1960 mediante las ayudas de la Alianza para el Progreso dadas por Estados Unidos.

No fue posible ubicar para este trabajo, programas de estudio emitidos entre 1979 y $1991^{30}$. El programa de Estudios Sociales de 1991 representa un salto cualitativo con respecto a los anteriores en tanto su construcción responde a criterios curriculares que podríamos señalar como semejantes a los actuales. En este programa (MEP, 1991, p. 9), se estableció un perfil educativo del III y IV ciclo, semejante a lo que ahora llamamos perfiles de salida en el cual se indicaba entre otros aspectos, que el estudiante debía ser "Defensor de los valores que

29 Según algunos investigadores consultados, durante la década de 1980 no se dieron modificaciones en los programas de estudio, presuntamente debido a las situaciones sociales, económicas y políticas que caracterizaron lo que algunos llaman la década perdida.

30 En el Plan de Estudios Sociales para la educación diversificada (IV ciclo) de 1991 la palabra "probidad" aparece sustituida por "dignidad". Este cambio, aunque sutil, demuestra que algunas de las personas vinculadas a la comisión redactora debieron advertir el peso ideológico que aquella tenía y por ello la sustituyeron. 
caracterizan a nuestro país como país democrático, de derecho y pacifista". Así mismo, en su presentación, propiamente en el apartado de conceptualización, el programa señalaba los propósitos de la asignatura de los Estudios Sociales y entre ellos decía "La asignatura desarrolla el conocimiento de las instituciones político administrativas que caracterizan al Estado Costarricense, y la probidad de quienes ejercen el poder político, lo que propicia el ejercicio permanente de la vida democrática" (MEP, 1991, p. 6) ${ }^{31}$. Dicho de otra manera, la reafirmación de la idoneidad de la clase política para gobernar estaba así explicada y justificada en función del desarrollo democrático más allá del desarrollo social, político o económico logrado en su larga trayectoria.

Esa idea de resaltar la probidad de la élite política sin embargo no se quedaba ahí. De este programa de 1991 -estructurado sobre objetivos, situaciones de aprendizaje y estrategias de evaluación- es digno de rescatar, a modo de ejemplo, una situación de aprendizaje de noveno año en la que este objetivo de exaltación política se reafirmaba. Una de las propuestas de trabajo pedía discutir

¿En qué medida el desarrollo del café, el tabaco, la minería, la imprenta, el respeto a la opinión, la apertura de caminos, la Campaña Nacional, el desarrollo de la educación, la Banca, el liderazgo de la oligarquía y otros fueron algunos factores básicos en la formación del Estado Costarricense entre 1821-1870? (MEP, 1991, p. 67)

Al leer con atención esta situación de aprendizaje, se pueden apreciar dos aspectos concretos. Por un lado, es necesario resaltar la complejidad de realizar un análisis medianamente adecuado sobre todos esos elementos en función del objetivo esperado, pero, por el otro, se advierte la importancia de resaltar el "liderazgo de la oligarquía" en la misma escala que la Campaña Nacional o el desarrollo educativo. Tal contenido, aunque referido al siglo XIX, puede entenderse en ejercicio de los intereses ideológicos que privaban en la clase política en un contexto donde su legitimidad empezaba a desmoronarse producto de su fragmentación interna pero también de las políticas neoliberales que se estaban ejecutando desde mediados de la década anterior bajo

31 Esta Política Educativa fue aprobada por el Consejo Superior de Educación en noviembre de 1994. 
la etiqueta de los Programas de Ajuste Estructural (PAE). Es claro que los PAE no solo afectaban a la clase obrera y al sector agrícola, sino también al sector de clase media urbano ligado a las instituciones estatales, y como se puede constatar, la movilidad laboral para la reducción del Estado puede rastrearse desde 1982 en los acuerdos con el Fondo Monetario Internacional (FMI) y concretamente desde 1990 en la administración de Rafael Ángel Calderón Fournier. Es decir, se dejó de lado la coyuntura actual (2018-2019), no podía existir un contexto más propicio para buscar formas de reafirmar la importancia de la clase política y de su probidad para gobernar.

En una revisión igualmente general de los programas de Estudios Sociales de 1995 (del III ciclo) se advierte, desde la presentación, la forma en que el gobierno de turno (a través del MEP) entendía el papel de la educación en esta materia. De forma arbitraria y con poco sentido de pertinencia, el Ministro de entonces aseguraba que

Los Programas de Estudio constituyen el proyecto de lo que debe ser la labor educativa en el aula, son la perspectiva, la expectativa, es decir, lo que se espera que se construya, que se aprenda, que se desarrolle. Los Programas de Estudio son la visión del pedagogo, como los planos lo son del ingeniero o el arquitecto. Más aún, son la herramienta del pedagogo, como el bisturí lo es del cirujano. (MEP, 1995, p. iii)

Basta con señalar dos aspectos concretos que se coligen de este pensamiento de un Ministro de Educación. Lo primero es que demuestra un desconocimiento absoluto de la labor que realiza un docente o maestro, al que describe genéricamente como un pedagogo -lo que obvia la complejidad de la pedagogía como ciencia-, pues lo reduce a un especialista en replicar contenidos o evaluar el cumplimiento de metas. Es decir, se despoja al docente de su capacidad creadora y adaptativa para "encajonarlo" en el cumplimiento de lo que se espera que sea enseñado. En segundo lugar, la idea de presentar el programa de estudio como una herramienta semejante al bisturí de un cirujano es más que elocuente sobre la visión e intención de homogenizar a la sociedad con "cortes precisos", definidos en términos de qué enseñar y qué no enseñar a los niños y jóvenes. Esta intención, que se asemeja a la idea de una producción fabril, se corresponde con la idea de "normalizar" a la sociedad con 
base en estándares definidos desde un conjunto de valores y actitudes que son presentadas como el ideal de ciudadano. Pero más que eso, tales orientaciones claramente buscaban formar a los futuros ciudadanos bajo un concepto de ciudadanía que respondiera a los objetivos de la clase hegemónica, en un contexto de cambio y agitación social.

Como ejemplo de esos cambios, entre 1986 y 1998 los gobiernos de Óscar Arias Sánchez (PLN), Rafael Ángel Calderón Fournier, del Partido Unidad Social Cristiana (PUSC) y José María Figueres Olsen (PLN) impulsaron una serie de medidas derivadas de los PAE, según los designios del FMI y del Banco Mundial (BM). Y para algunos estudiosos del desarrollo costarricense, esta coyuntura coincidió con la transición del PLN -y también del PUSC- desde una posición ideológica de centro-izquierda hacia otra de centro-derecha (Gudmundson, 2018), que comulgaba de cerca con las ideas neoliberales que defienden la importancia del mercado y de la iniciativa privada. En el marco de esas transformaciones económicas e institucionales, desde las cuales se impulsaba, de forma abierta, los tratados de libre comercio, la educación venía a jugar un papel central. Probablemente, eso explica por qué en la fundamentación de los Programas de Estudios Sociales de 1995 el eje sobre ética del desarrollo y de la sustentabilidad hacía referencia a la Política Educativa "Hacia el Siglo XXI" (MEP, 1995, p. 2) 32, según la cual se procuraba "formar un ciudadano que como consumidor incorpore criterios de durabilidad e impacto ambiental y como productor evite el desperdicio y la contaminación" (MEP, 1995, p. 9).

Esta noción de ciudadano consumidor vendría a ser fundamental para explicar parte de las políticas desarrolladas en los años posteriores a la ejecución de los PAE. El desarrollo social, económico, político y tecnológico que siguió a estos procesos transformaría a la sociedad costarricense de una forma sin precedentes, al acentuar la marginalidad y exclusión tanto en el campo como en la ciudad. De tal forma, la posibilidad de consumir (moda, tecnología, arte, etc.) se erigió como uno de los "nuevos derechos" a promocionar entre las generaciones jóvenes, al tiempo que este se equiparaba a la condición de "salud económica" del país. Dicho en otras palabras, el acceso a crédito de consumo y la amplia gama de ofertas de las que podía disponer un ciudadano se

32 Esta Política Educativa fue aprobada por el Consejo Superior de Educación en noviembre de 1994. 
convirtieron en sinónimo del éxito del modelo de desarrollo económico impulsado durante la década de 1990. Al mismo tiempo, esta "bonanza" debía servir para reafirmar viejos valores ciudadanos asociados con la evolución pacífica de la democracia costarricense. En consonancia con eso, entre los objetivos generales el plan de Estudios Sociales (MEP, 1995, p. 13) se proponía "Reconocer y aplicar los valores, normas y tradiciones que le son propias a la cultura local, regional y nacional para rescatarlos, retroalimentarlos, reconstruirlos y consolidarlos, tales como: el amor a la patria, la honestidad, la puntualidad...".

Las confrontaciones de la sociedad con el Estado entre finales del 1999 y el 2000, de forma particular en contra del denominado Combo del ICE ${ }^{33}$, le mostró a la élite política que la sociedad no era la que $20 \mathrm{o}$ 30 años atrás iba a los procesos electorales a votar por colores políticos como una tradición. Esta situación cambiaría radicalmente la forma de hacer política; un ejemplo de ello fue la desaparición de las famosas plazas públicas donde los partidos salían a medir su caudal electoral. Este cambio parece no ser ajeno a lo que se hizo después en los programas de Estudios Sociales, pues el "sustrato ideológico" se volvió más sutil y se desplazó de los contenidos propiamente conceptuales o procedimentales, al conjunto de valores y actitudes que se pretendía impulsar en los jóvenes mediante esta asignatura. Pero más llamativo es que en el programa del III ciclo de 2001, luego de las secciones de contenidos se incluyó un conjunto de anexos entre los cuales es pertinente rescatar el número cuatro relativo a la "La solución pacífica de los conflictos. El mejor camino para lograr la paz" (MEP, 2001, p, 63). Este eje en sí mismo es laudable, pero es preciso comprenderlo en el contexto que se expone, pues de alguna forma refleja la intención del Estado por mitigar la efervescencia social y la acción colectiva que se hacía cada vez más recurrente. Según el Programa del Estado de la Nación (PEN), en el año 2000 se presentaron 613 acciones colectivas de distinta naturaleza y entre 2000 y 2005 se acumuló un total de 2687 manifestaciones (García, 2009).

En el programa de educación diversificada de 2005 puede rescatarse como ejemplo el objetivo de "Analizar los principales desafíos

33 Proyecto impulsado por Miguel Ángel Rodríguez Echeverría (presidente 1998-2002) que intentaba abrir el monopolio de las telecomunicaciones. La sociedad entendió este proyecto como un intento de privatización y reaccionó con protestas multitudinarias y multisectoriales que obligaron al gobierno a retirar el proyecto. 
que afronta la sociedad costarricense en la actualidad" (MEP, 2005, p. 39). Aunque en los contenidos a tratar se cita, de forma explícita el tema de la corrupción, no existen procedimientos específicos para tratarlo y en la columna de valores y actitudes se propone muy sutilmente reflexionar "ante la crisis de los valores de la sociedad costarricense". Pero más interesante aún es el tema de "Desafíos de la equidad y la exclusión" sobre el que no se advierte siquiera un procedimiento o el desarrollo de una actitud. Basta reconocer que la pobreza general entre 2000 y 2004 no bajó de $20 \%$ para entender que al Gobierno le venía bien la discusión enfocada en los retos de la equidad en lugar del análisis sobre las causas estructurales de la inequidad. Este tipo de enfoques, menos perceptibles y más orientados a crear la idea de que eso "está en proceso de resolverse", contribuían a diluir claramente la crítica por la falta de atención a problemas medulares como la pobreza, la exclusión social y la marginalidad que cada vez son más notorias en el país. Pero, además, para cerrar las "veredas" que la crítica podía aprovechar se pedía como colorario de este tema, desarrollar "Criticidad ante la violencia e intransigencia de la ciudadanía" (MEP, 2005, p. 39). Es claro que la violencia no es, ni lo será nunca, la salida a los problemas actuales de ningún país, pero catalogar las protestas ciudadanas y la crítica social como intransigencia es un claro ejemplo del malestar que estos movimientos sociales articulados o espontáneos le causaban a la institucionalidad en su conjunto.

Con respecto a los programas aprobados por Leonardo Garnier (2014) y Sonia Marta Mora (2016) no se expondrán ejemplos específicos en este trabajo. Se hace la invitación para que el estimado lector pueda conocerlos y analizarlos por su cuenta a fin de determinar la forma en que cada uno ofrece posiciones ideológicas concretas. No obstante, también se le recuerda al lector que después de la década de 1990, más allá de lo establecido en los programas, el peso ideológico de los Estudios Sociales está estrechamente relacionado con el papel del docente en su proceso de mediación. La labor del educador, formado especialmente en las universidades públicas, ha fortalecido la conciencia crítica y el análisis riguroso de la sociedad, la economía y el gobierno, lo cual contribuyó a crear un punto de inflexión en la relación entre la sociedad civil y los gobiernos de turno; hito que, si bien podría ubicarse mucho antes, es entre el "Combo ICE" y las protestas contra el Tratado de Libre Comercio con Estados Unidos donde cobra mayor vigencia. 


\section{El componente ideológico a través del tamiz de educadores}

Sería iluso pensar que todos los docentes costarricenses asumen con el mismo ahínco el papel político de la educación, o incluso que todos lo tienen claro. Sin embargo, a manera de hipótesis se plantea que el papel ideológico desarrollado por los Estudios Sociales depende en gran medida de la acción consciente e inconsciente de los educadores. Bajo este principio, y siempre a manera de hipótesis, las diferencias pueden establecerse cuando la educación es asumida:

I. Por docentes que son seguidores de la visión de Estado impulsada por el bipartidismo histórico (PLN-PUSC).

II. Por docentes acríticos que reproducen los contenidos de los programas y su enfoque ideológico, en ocasiones sin ser conscientes.

III. Por docentes críticos que se ocupan de deconstruir históricamente la evolución del país desde sus cimientos. En este caso no solo se valora el desarrollo socioeconómico, sino el sistema democrático en su conjunto y se examina a la luz de la realidad global.

IV. Por docentes que, como ciudadanos políticos, comulgan con posturas ideológicas diferentes a las del bipartidismo histórico. En este caso, las posiciones que van de la extrema izquierda a la derecha extrema, o incluso desde posiciones anárquicas.

V. Por docentes que, sin militancia político-ideológica alguna, reaccionan con indignación ante lo que ven como una mala conducción del Estado y los actos de corrupción cometidos por algunos gobiernos.

Si se sigue esta tipología puede decirse que, mientras existan docentes críticos, el sistema será cuestionado y los Estudios Sociales continuarán teniendo un papel clave, cuya profundidad y madurez dependerá del buen o mal ejercicio formativo que desarrollen las universidades en la preparación de profesionales. Y, por otro lado, quizás solo sea una extraña coincidencia, pero es interesante que este contexto donde surgió la polémica sobre ideologización de los Estudios Sociales coincidió con una coyuntura donde la crisis fiscal hizo a las universidades públicas un blanco de ataque por parte de algunos sectores de la clase política. ¿Será acaso que los intentos por recortar el presupuesto a las universidades y someterlas a controles más rígidos coincide con una 
lectura de la clase política sobre la necesidad de contener el accionar de estos centros de enseñanza? La pregunta parece digna de un debate y cobra mayor pertinencia cuando se escuchan rumores sobre iniciativas para modificar artículos constitucionales que otorgan autonomía a las universidades públicas de este país.

\section{Unas palabras de cierre}

Este breve repaso aporta al menos dos aspectos puntuales que es oportuno retomar. De un lado, parece incuestionable que los programas de Estudios Sociales desde la década de 1970 jugaron un rol ideológico fundamental en la construcción de una sociedad pensada desde la clase política con el fin de convertirla en una especie de "virtuosa de la democracia". Democracia entendida eso sí, desde una visión reducida, que la limitaba a la incorporación de valores patrios, respeto a la autoridad, así como admiración de próceres e incluso abnegación en beneficio de un interés supuestamente colectivo. El corpus ideológico que sustentaba esta visión país fue transitando desde formas explícitas en los contenidos hasta representaciones más sutiles en forma de valores, actividades o procedimientos de aprendizaje. Del mismo modo, pero en sentido inverso, este tránsito fue acompañado por la transformación del plantel docente, al pasar de aquellos con poca preparación y formados por corrientes positivistas, a los educadores graduados de las universidades públicas que particularmente desde la década de 1990 vienen formándose en ambientes dominados por corrientes críticas.

Por otro lado, los argumentos trabajados en este documento permiten asegurar que esta polémica sobre la ideologización que promueven los Estudios Sociales evidencia que aquellos que antes se servían o beneficiaban de estas prácticas hoy se sienten atacados y vulnerables ante el escrutinio que se hace desde las aulas y que se materializa en las calles mediante manifestaciones y denuncias que, entre otras cosas, ha conducido a procesos judiciales contra varios expresidentes. Esa situación también afecta los intereses del bipartidismo histórico, en un contexto donde intentan recobrar liderazgo o legitimidad tras una debacle sin precedentes e incluso de pérdida de caudal electoral. Algo semejante podría decirse de otras agrupaciones que, en un contexto de fragmentación política como el actual, buscan ganar capital político deslegitimando al partido en el poder. 
Y como consecuencia lógica de todo lo expresado en este trabajo, es crucial reafirmar que los Estudios Sociales no pueden ni deben perder ese papel de escrutinio y crítica ideológica. Por el contrario, en un mundo donde las dimensiones espacio temporales de los fenómenos que nos afectan son casi idénticas para todas las naciones y donde muchos de los problemas se han convertido en condiciones globales -inseguridad, tráfico de drogas, cambio climático, desaceleración económica, inequidad y exclusión, etc.- se demanda una educación cada vez más comprometida con el análisis de los problemas en una perspectiva local-regional-global. En este sentido, los Estudios Sociales y particularmente los docentes de esta asignatura están llamados a desempeñar un papel activo en la formación de los ciudadanos del siglo XXI. Ciudadanos que, si bien crecerán en un ambiente de incertidumbre e individualismo, deben al menos saber qué tanto su futuro como el del planeta mismo depende de la colectividad y de cómo esta decida tomar las decisiones políticas que le permitan siquiera mantener su estilo de vida actual.

\section{Referencias}

Academia Costarricense de la Lengua. (1967). Los libros de texto "ODECA" - "ROCAP" destinados a la Escuela Primaria". Boletín de la Academia Costarricense de la Lengua, XI(18/19), 2-24. Recuperado de https://acl.cr/BACL_I_1819.pdf

Agüero, J., Araya, I., Marín, J., Molina, S., y Rojas, F. (2011). La Enseñanza de los Estudios Sociales y la Educación Cívica: hacia una profesión interdisciplinar. Diálogos: Revista Electrónica de Historia, 12(2), 26-48. Recuperado de https://revistas.ucr.ac.cr/ index.php/dialogos/article/view/6355

Althusser, L. (1988). Ideología y aparatos ideológicos del Estado: Freud y Lacan. Buenos Aires, Argentina: Nueva Visión.

Apple, M. (2008). Ideología y currículum. (Rafael Lassaletta, Trad.). Madrid, España: Ediciones Akal S. A.

García, A. (2009). Acciones colectivas y actores político-sociales en el año 2009. Decimosexto Informe Estado de la Nación en Desarrollo Humano Sostenible. Recuperado de https://www.researchgate.net/publication/311738356_Acciones_colectivas_y_actores_politico-sociales_en_el_ano_2009 
Giroux, H. (2004). Teoría y resistencia en educación. Una pedagogía para la oposición (6ta ed. en español) (Ada Teresita Méndez. Trad.). México: Siglo XXI editores, en coedición con el Centro de Estudios sobre la Universidad, UNAM.

Gudmundson, L. (1990). Costa Rica antes del café. 1ed., en español. San José, Costa Rica: Editorial Costa Rica.

Gudmundson, L. (2018). Costa Rica después del café. La era cooperativa en la historia y la memoria. San José, Costa Rica: EUNED.

Hoogerwerf, A. (1969). Despolitización y empobrecimiento de la ideología: Un análisis teórico. Revista Española de la Opinión Pública, 16, 15-31. Recuperado de https://www.jstor.org/ stable/40199132

Jarpa, C. (2015). Función política de la educación en el pensamiento de Antonio Gramsci. Cinta Moebio, 53, 124-134. Recuperado de https://www.researchgate.net/publication/282834308_Funcion_politica_de_la_educacion_en_el_pensamiento_de_Antonio_Gramsci

Ley 2160. (1957). Ley Fundamental de Educación. Asamblea Legislativa de Costa Rica.

Mainer J. (1998). La educación histórica como proyecto de contrasocialización. Aula-Historia Social, 2, 73-80. Fundación Instituto de Historia Social. Recuperado de https://www.jstor.org/ stable $/ 40343300$

McLaren, P. (2005). La vida en las escuelas. Una introducción a la pedagogía crítica en los fundamentos de la educación (4 de. en español) (Cotejo y traducción de la cuarta edición Susana Guardado Del Castro). México: Siglo XXI Editores.

MEP. (1971). Programa de Estudios Sociales I-II-III ciclos. San José, Costa Rica: Departamento de currículum.

MEP. (1978a). Programa de Estudios Sociales III ciclo. San José, Costa Rica: Dirección General de Educación Académica. Departamento de Asesorías y Supervisión.

MEP. (1978b). Programa de Estudios Sociales X año. San José, Costa Rica: Dirección General de Educación Académica. Departamento de Asesorías y Supervisión.

MEP. (1979). Educación Diversificada Estudios Sociales X. Curso opcional y básico. San José, Costa Rica: Dirección General de Educación Académica. Departamento de Asesorías y Supervisión. 
MEP. (1991). Programa de Estudios III ciclo. San José, Costa Rica: División de planeamiento y desarrollo educativo.

MEP. (1995). Programa de Estudios Sociales III ciclo. San José, Costa Rica: El Ministerio.

MEP. (2001). Programa de Estudios Sociales III ciclo. San José, Costa Rica: El Ministerio.

MEP. (2005). Programa de Estudios Sociales. Educación Diversificada. San José, Costa Rica: El Ministerio.

Newland, C. (1994). The Estado Docente and Its Expansion: Spanish American Elementary Education, 1900-1950. Journal of Latin American Studies, 26(2), 449-467. Recuperado de https://www. jstor.org/stable/157951

Organización de Estados Iberoamericanos. (1997). Sistema Educativo Nacional de Costa Rica. Recuperado de https://www.oei.es/ historico/quipu/costarica/\#sis

Rachik, H. (2006). Identidad dura e identidad blanda. CIDOB d'Afers Internacionals, 73/74, 9-20. Recuperado de https://www.jstor. org/stable $/ 40586224$

Retana, C. (2010). Currículo de la Educación Media Costarricense de 1950 a 2010. Recuperado de http://repositorio.conare.ac.cr/ handle/20.500.12337/773

Salas, J. (2000). La incorporación de los Estudios Sociales como materia de estudio escolar en Costa Rica y la necesidad de su reconceptualización de cara a los desafíos para la educación a inicios del siglo XXI. Perspectivas: Revista de Estudios Sociales y Educación Cívica, 1/2, 51-70. Recuperado de https://www.revistas. una.ac.cr/index.php/perspectivas/article/view/3849

Solano, E. (2006). ¿Enseñamos estudios sociales o historia? Revista Electrónica Actualidades Investigativas en Educación, 6(2), 1-21. Recuperado de https://revistas.ucr.ac.cr/index.php/aie/ article/view/9213

Soto, E. y Herrera, M. (1998). Análisis retrospectivo de la práctica educativa en la enseñanza de los Estudios Sociales, 1958-1978. (Tesis de Licenciatura en la Enseñanza de los Estudios Sociales no publicada). Universidad Nacional (UNA), Heredia, Costa Rica.

Ovares, F. (1977). Educación como integración ideológica. Lectura crítica de los textos ODECA-ROCAP. San José, Costa Rica: Editorial Territorio, Colección DEI. 
Vázquez, G. (2015). La necesidad educativa de lo político. En A. Colom., J. García, P. Pérez, T. Rodríguez, J. Sarramona, J. Touriñán, y G. Vázquez (Eds.), Política y Educación. Desafios y propuestas (pp. 11-38). Madrid: Dykinson, S. L. Recuperado de https:// www.jstor.org/stable/j.ctt1k235zs.3 
